\title{
Set-up of a population-based familial breast cancer registry in Geneva, Switzerland: validation of first results
}

\author{
H. M. Verkooijen ${ }^{1}$, G. Fioretta ${ }^{1}$, P. O. Chappuis ${ }^{2,3}$, G. Vlastos ${ }^{4}$, A. P. Sappino ${ }^{2}$, S. Benhamou ${ }^{5} \&$ \\ C. Bouchardy ${ }^{1 *}$ \\ ${ }^{1}$ Geneva Cancer Registry, Institute for Social and Preventive Medicine, Geneva University, Geneva; Divisions of ${ }^{2}$ Oncology and ${ }^{3}$ Medical Genetics, \\ Department of Obstetrics and Gynecology and ${ }^{4}$ Department of Obstetrics and Gynecology, Geneva University Hospitals, Geneva, Switzerland; \\ ${ }^{5}$ INSERM and Evry University, Evry, France \\ Received 5 May 2003; accepted 23 October 2003
}

\begin{abstract}
Background: This article evaluates the accuracy of family history of breast and ovarian cancer among firstdegree relatives of breast cancer patients, retrospectively collected during the setting up of a population-based family breast cancer registry.

Patients and methods: Family histories of cancer for all women with breast cancer recorded at the Geneva Cancer Registry from 1990 to 1999 were retrospectively extracted from medical files. The accuracy of these family histories was validated among Swiss women born in Geneva: all 119 with a family history of breast $(n=110)$ or ovarian $(n=9)$ cancer and a representative sample of 100 women with no family history of breast or ovarian cancer. We identified the first-degree relatives of these women with information from the Cantonal Population Office. All first-degree relatives, resident in Geneva from 1970 to 1999, were linked to the cancer registry database for breast and ovarian cancer occurrence. Sensitivity, specificity and level of overall agreement $(\kappa)$ were calculated.

Results: Among 310 first-degree relatives identified, 61 had breast cancer and six had ovarian cancer recorded at the Geneva Cancer Registry. The sensitivity, specificity and $\kappa$ of the reported family histories of breast cancer were $98 \%, 97 \%$ and 0.97 , respectively. For ovarian cancer, the sensitivity, specificity and $\kappa$ were $67 \%, 99 \%$, and 0.66 , respectively.

Conclusions: This study indicates that retrospectively obtained family histories are very accurate for breast cancer. For ovarian cancer, family histories are less precise and may need additional verification.

Key words: breast cancer, familial cancer registry, ovarian cancer, population based, validation
\end{abstract}

\section{Introduction}

Breast cancer is the most common malignancy among women in industrialised countries and the Swiss canton of Geneva presents one of the highest incidence rates worldwide [1]. A family history of breast and/or ovarian cancer is one of the strongest known risk factors for breast cancer [2]. Several epidemiological studies have demonstrated that female relatives of breast cancer patients are at increased risk of developing breast cancer and that the extent of this risk varies according to the degree of the genetic relationship with the affected relative, age at onset of breast cancer in the relative and total number of affected relatives [3-6]. Family history of breast cancer is an important parameter in statistical models, developed to determine cumulative breast cancer risk $[7,8]$ or to evaluate the probability of carrying a genetic predisposition for breast or ovarian cancer [9]. Two major dominantly inherited genes predisposing to breast and ovarian cancer have

\footnotetext{
*Correspondence to: Dr C. Bouchardy, Geneva Cancer Registry,

55 Boulevard de la Cluse, 1205 Geneva, Switzerland.

Tel: +41-22-329-1011; Fax: +41-22-328-2933;

E-mail: christine.bouchardymagnin@imsp.unige.ch
}

been identified, $B R C A 1$ and $B R C A 2$. These germ-line mutations account for $5-10 \%$ of all breast and ovarian cancers [10]. Therefore, a large proportion of the familial clustering of breast and ovarian cancer remains unexplained. Particular clinicopathological characteristics and differences in outcome have been reported for cases of breast cancer developing in familial clusters compared to sporadic cases [11].

Innumerable research groups all over the world work to unravel the complex relation between family history of breast cancer and increased risk of developing the disease. Population-based familial cancer registries are of great value in assessing the importance of family history on breast cancer risk in a defined population and permit epidemiological research on etiology, clinico-pathological characteristics, management and outcome of women with familial breast cancer. However, the number of population-based cancer registries is relatively low $[12,13]$.

In the Swiss canton of Geneva a population-based familial breast cancer registry has recently been established [14]. This registry includes all women diagnosed with breast cancer in the canton since 1990. For cases diagnosed from 1990 to 1999, family history was retrospectively retrieved using information from 
hospital files and files of private physicians. A few studies have assessed the accuracy of reported family history. Most of these studies involved selected patients referred to genetic counselling units [15-18] or included in a case-control study [19]. To our knowledge, only one population-based breast cancer registry was validated by comparing the information in the familial cancer registry database with that obtained by personal interviews [20].

In this study, we present the results of the validation of reported family histories of breast and ovarian cancer among first-degree relatives in the Geneva population-based familial breast cancer registry.

\section{Patients and methods}

The Geneva Familial Breast Cancer Registry was created in the framework of the Geneva Cancer Registry. Briefly, the Geneva Cancer Registry records all incident cancers occurring in the population of the canton ( 420 000 inhabitants) since 1970. It collects information from various sources, and is considered accurate, as attested by its very low percentage $(<2 \%)$ of cases recorded from death certificates only [21]. All hospitals, pathology laboratories and private practitioners in the canton are requested to report all cancer cases. Trained tumor registrars systematically abstract data from medical and laboratory records. Physicians regularly receive inquiry forms to secure missing clinical and therapeutic data. Death certificates are consulted systematically. Recorded data include socio-demographic information, method of discovery, type of confirmation, tumor characteristics (coded according to the International Classification of Diseases for Oncology) [22], stage of disease at diagnosis, hormonal receptor status, treatment during the first 6 months after diagnosis, survival status and cause of death.

The Geneva Familial Breast Cancer Registry includes all women diagnosed with breast cancer in the Geneva population since 1990. For the women diagnosed from 1990 to 1999, we retrospectively collected information on family history of cancer according to a standard questionnaire, using information from medical records from the public university hospital and private physicians. The retrospectively retrieved information on family history of breast and ovarian cancer among first-degree relatives was validated. This validation study comprised all Swiss breast cancer patients born in Geneva who had at least one relative with breast cancer $(n=110)$ or ovarian cancer $(n=9)$, and a random sample of 100 Swiss patients, born in Geneva, who had no family history of breast or ovarian cancer. For each of those 219 patients, we identified all female first-degree relatives with information from the Cantonal Population Office. This institution is in charge of the registration of sociodemographic information of actual and previous inhabitants of the Geneva canton. All first-degree relatives, who were resident in the canton from 1970 (the start of the Geneva cancer registry) to 1999, were then linked to the
Geneva Cancer Registry database. Thus, all first-degree relatives diagnosed with breast or ovarian cancer were ascertained.

By comparing the retrospectively obtained family histories with the combined information of the Cantonal Population Office and the Geneva Cancer Registry, we calculated sensitivity, specificity and predictive values of the reported family histories using standard statistic procedures. The information obtained from the Cantonal Population Office in combination with the Geneva Cancer Registry was taken as reference standard. Level of agreement between reported and validated familial breast cancer histories, corrected for the agreement due to chance only, was evaluated using the $\kappa$ statistic [23].

\section{Results}

From 1990 to 1999, 2957 women were diagnosed with invasive breast cancer in the canton of Geneva. We found information on family history of breast cancer for 2648 (90\%) of these women. A total of $433(16 \%)$ women were of Swiss nationality and born in Geneva: $110(25 \%)$ reported a family history of breast cancer, nine $(0.6 \%)$ a family history of ovarian cancer.

For the 119 women with a family history and the random sample of 100 women without a family history included in the validation set, we identified 310 first-degree relatives, who were resident in Geneva from 1970 to 1999 (109 mothers, 75 identified sisters and 134 daughters).

After linkage of these first-degree relatives with the Geneva Cancer Registry database, 61 appeared to have been diagnosed with breast cancer and six with ovarian cancer.

The results of the validation of the reported family history of breast cancer among first-degree relatives is presented in Table 1. The accuracy of the reported family history on breast cancer was high. Only two mothers were incorrectly reported as having had breast cancer (false positives): one mother was diagnosed with bladder cancer and the other one was never diagnosed with cancer. For one mother, no history of breast cancer was reported, while in fact she had been diagnosed with breast cancer (false negative). The accuracy of the reported history of breast cancer for sisters and daughters was also very high. Taking all first-degree relatives (mothers, sisters and daughters) together, the sensitivity, specificity, positive and negative predictive values of the reported family history of breast cancer were 98\%, 97\%, 97\% and 100\%, respectively. The overall level of concordance between the reported family history of breast cancer and the family history according to the combined information of the Cantonal Popula-

Table 1. Validation of reported history of breast cancer among first-degree relatives of 219 women diagnosed with breast cancer

\begin{tabular}{|c|c|c|c|c|c|c|c|c|c|}
\hline & \multirow[t]{2}{*}{$n$} & \multicolumn{2}{|c|}{$\begin{array}{l}\text { Positive } \\
\text { family history }^{\mathrm{a}}\end{array}$} & \multicolumn{2}{|c|}{$\begin{array}{l}\text { Negative } \\
\text { family history }^{\mathrm{a}}\end{array}$} & \multirow[t]{2}{*}{$\begin{array}{l}\text { Sensitivity, } \\
\%\end{array}$} & \multirow[t]{2}{*}{$\begin{array}{l}\text { Specificity, } \\
\%\end{array}$} & \multicolumn{2}{|c|}{ Predictive value, $\%$} \\
\hline & & $\mathrm{BC}^{+}$ & $\mathrm{BC}^{-}$ & $\mathrm{BC}^{+}$ & $\mathrm{BC}^{-}$ & & & Positive & Negative \\
\hline Mothers & 109 & 39 & 2 & 1 & 67 & 98 & 97 & 95 & 99 \\
\hline Sisters & 67 & 18 & 0 & 0 & 49 & 100 & 100 & 100 & 100 \\
\hline Daughters & 134 & 3 & 0 & 0 & 131 & 100 & 100 & 100 & 100 \\
\hline All FDRs & 310 & 60 & 2 & 1 & 247 & 98 & 97 & 97 & 100 \\
\hline
\end{tabular}

${ }^{\mathrm{a}}$ As reported in the medical records.

$\mathrm{BC}^{+}$, presence of breast cancer; $\mathrm{BC}^{-}$, absence of breast cancer; FDR, first-degree relative. 
Table 2. Validation of reported history of ovarian cancer among first-degree relatives of 219 women diagnosed with breast cancer

\begin{tabular}{|c|c|c|c|c|c|c|c|c|c|}
\hline & \multirow[t]{2}{*}{$n$} & \multicolumn{2}{|c|}{$\begin{array}{l}\text { Positive family } \\
\text { history }^{\mathrm{a}}\end{array}$} & \multicolumn{2}{|c|}{$\begin{array}{l}\text { Negative family } \\
\text { history }^{\mathrm{a}}\end{array}$} & \multirow[t]{2}{*}{$\begin{array}{l}\text { Sensitivity, } \\
\%\end{array}$} & \multirow[t]{2}{*}{$\begin{array}{l}\text { Specificity, } \\
\%\end{array}$} & \multicolumn{2}{|c|}{ Predictive value, $\%$} \\
\hline & & $\mathrm{OC}^{+}$ & $\mathrm{OC}^{-}$ & $\mathrm{OC}^{+}$ & $\mathrm{OC}^{-}$ & & & Positive & Negative \\
\hline Mothers & 109 & 3 & 2 & 1 & 103 & 75 & 98 & 60 & 99 \\
\hline Sisters & 67 & 1 & 0 & 1 & 65 & 50 & 100 & 100 & 98 \\
\hline All FDRs & 176 & 4 & 2 & 2 & 168 & 67 & 99 & 67 & 99 \\
\hline
\end{tabular}

${ }^{\text {a } A s ~ r e p o r t e d ~ i n ~ t h e ~ m e d i c a l ~ r e c o r d s . ~}$

$\mathrm{OC}^{+}$, presence of ovarian cancer; $\mathrm{OC}^{-}$, absence of ovarian cancer; FDR, first-degree relative.

tion Office and the Geneva Cancer Registry was very high [ $\kappa$ score, 0.97 ; $95 \%$ confidence interval (CI) 0.94-1.0] [23].

For ovarian cancer, the reported family history among firstdegree relatives was less accurate (Table 2). Five women reported ovarian cancer in their mothers, but in two cases, this was erroneous, as both mothers were in fact diagnosed with endometrial cancer (false positives). One mother and one sister were incorrectly not reported to have had ovarian cancer (false negatives). Taking mothers and sisters together (daughters were excluded from this analysis, because there were no daughters reported to have had ovarian cancer and we did not identify any daughters with ovarian cancer during validation), the sensitivity, specificity, positive and negative predictive values of the reported family history of ovarian cancer were $67 \%, 99 \%, 67 \%$ and $99 \%$, respectively. The overall level of concordance between the reported family history of ovarian cancer in mothers and sisters and the family history according to the combined information of the OCP (Cantonal Population Office) and the Geneva cancer registry was substantially lower than that for breast cancer. The $\kappa$ score was 0.66 (95\% CI 0.34-0.97) indicating an 'acceptable' agreement [23].

\section{Discussion}

This study has indicated that the retrospectively obtained family histories of the Geneva Familial Breast Cancer Registry are very accurate for breast cancer, whereas for ovarian cancer they are less accurate, but because a comparably low validity of reported family histories of ovarian cancer has also been reported in prospective validation studies [17, 19], it is probably not due to the retrospective nature of the data collection. Lack of knowledge and clarity on ovarian cancer are likely to hamper accurate reporting of ovarian cancer among family members.

Anton-Culver et al. [20] have validated the family histories of breast cancer among mothers and sisters of breast cancer patients. Family history was obtained in a similar manner as ours i.e. in the context of a population-based cancer registry using information from medical records. They used personal interviews to ascertain the collected family histories of cancer. Sensitivity and specificity for a family history of breast cancer among 216 mothers were high (92\% and 99\%, respectively) and comparable to the results of our study. For 177 sisters, the sensitivity was somewhat lower $(88 \%)$ and the specificity was comparable (99\%). Douglas et al. [16] studied the accuracy of family history of breast cancer, reported by affected and non-affected female visitors of a genetics department. The reported family histories of breast cancer were verified using death certificates, medical notes, histopathology reports and cancer registry data. Around $95 \%$ of the reported breast cancer cases among family members were accurate, while for ovarian cancer $83 \%$ of the reported cases were confirmed. In a large casecontrol study, validation of family histories of cancer has demonstrated important differences in sensitivity and overall agreement for reported family history of breast cancer $(83 \% ; \kappa, 0.63)$ compared to family history of ovarian cancer $(60 \% ; \kappa, 0.36)[19]$.

Reasons for false-positive family histories (i.e. specific cancer in relative reported by proband, while in fact this person was never diagnosed with this particular cancer) are diverse. In a small proportion of erroneous family histories, benign diseases are mistakenly reported as cancer, but more often it is the primary site that is incorrect [16]. For all cancers, the primary cancer site is correctly identified in around $64-86 \%$ of cases [18]. Our data are in concordance with these findings: in our series, one of the two false-positive family breast cancer cases was in fact bladder cancer, while the other one was no cancer at all. Both falsely reported family histories of ovarian cancer were in fact uterine cancer cases. Fictitious family histories of cancer also occur, and there have even been some rare reports of intentionally fabricated untrue family histories [16, 24].

There are several shortcomings in our study. First, we limited our study to first-degree relatives of breast cancer patients. Because of the methodological approach we choose, identification of second- and third-degree relatives of the breast cancer patients in the cohort would have been too complicated and inaccurate, as the information on second- and third-degree relatives at the Cantonal Population Office is far less complete and more difficult to extract. Nevertheless, occurrence of breast or ovarian cancer in second- or third-degree relatives is also associated with individual breast cancer risk and accurate reporting is therefore also very important for these relatives. This is of particular relevance in genetic counselling, in case of small pedigrees and breast cancer occurrence in the paternal side of the family. We know from previous studies that the accuracy of history of breast and ovarian among second- and third-degree relatives is generally less accurate than for first-degree relatives. Eerola et al. [15] reported a sensitivity of breast or ovarian cancer history among first and second-degree relatives of $100 \%$ and $99 \%$, respectively, but this dropped to $61 \%$ for third-degree relatives. Similarly, in another study, the percentage of accurately reported breast cancer 
histories was $94 \%$ for first-degree relatives, $90 \%$ for seconddegree relatives and $75 \%$ for third-degree relatives [17].

A second shortcoming of our study was that we were only able to validate the family history of relatives that were resident in Geneva from 1970 to 1999 , because only these women were covered by the Geneva Cancer Registry. One could postulate that reported family history for these women is more accurate than for relatives who have deceased before 1970 or who live abroad, which is not uncommon in the cosmopolitan population of Geneva where $30-40 \%$ of the population are foreigners. Nevertheless, we accepted this loss of generalisability in order to gain in the accuracy of the data. Where other studies used personal interviews to confirm family history of cancer, leaving room for recall bias, intentional fictitious family history, unintentional errors, etc., we are confident that the results we have obtained are very accurate.

In conclusion, this study has demonstrated that it is possible to obtain a reliable family history of breast cancer in first-degree relatives by systematic, retrospective consultation of medical records. However, our study confirmed that reported family history for ovarian cancer was less accurate. Therefore, familial patterns of ovarian cancer require additional verification, particularly when this information is used for cancer risk assessment and discussions on screening procedures and preventive options.

\section{Acknowledgements}

We thank Mrs M. Feser, Mrs D. Perrodin and Mrs A. Ionescu for their assistance in data collection and Mrs S. Blagojevic for editorial assistance. The Geneva Familial Breast Cancer Registry was established with the financial support of the Geneva Cancer League. Dr H.M.Verkooijen was financially supported by PROSPER grant No. 3233-069350 from the Swiss National Science Foundation.

\section{References}

1. Parkin DM, Whelan SL, Ferlay J et al. Cancer Incidence in Five Continents, Vol. VII. Lyon, France: IARC Scientific Publications 1997.

2. Armstrong K, Eisen A, Weber B. Assessing the risk of breast cancer. N Engl J Med 2000; 342: 564-571.

3. Collaborative Group on Hormonal Factors in Breast Cancer. Familial breast cancer: collaborative reanalysis of individual data from 52 epidemiological studies including 58209 women with breast cancer and 101 986 women without the disease. Lancet 2001; 358: 1389-1399.

4. Hemminki K, Granstrom C, Czene K. Attributable risks for familial breast cancer by proband status and morphology: a nationwide epidemiologic study from Sweden. Int J Cancer 2002; 100: 214-219.

5. Colditz GA, Willett WC, Hunter DJ et al. Family history, age, and risk of breast cancer. Prospective data from the Nurses' Health Study. JAMA 1993; 270: 338-343.
6. Pharoah PD, Day NE, Duffy S et al. Family history and the risk of breast cancer: a systematic review and meta-analysis. Int J Cancer 1997; 71: 800-809.

7. Gail MH, Brinton LA, Byar DP et al. Projecting individualized probabilities of developing breast cancer for white females who are being examined annually. J Natl Cancer Inst 1989; 81: 1879-1886.

8. Claus EB, Risch N, Thompson WD. Autosomal dominant inheritance of early-onset breast cancer: implications for risk prediction. Cancer 1994; 73: 643-651.

9. Parmigiani G, Berry D, Aguilar O. Determining carrier probabilities for breast cancer-susceptibility genes $B R C A 1$ and $B R C A 2$. Am J Hum Genet 1998; 62: 145-158.

10. Nathanson KL, Wooster R, Weber BL et al. Breast cancer genetics: what we know and what we need. Nat Med 2001; 7: 552-556.

11. Chappuis PO, Rosenblatt J, Foulkes WD. The influence of familial and hereditary factors on the prognosis of breast cancer. Ann Oncol 1999; 10: 1163-1170.

12. Hemminki K, Vaittinen P. National database of familial cancer in Sweden. Genet Epidemiol 1998; 15: 225-236.

13. Olsen JH, Boice JD, Seersholm N et al. Cancer in the parents of children with cancer. N Engl J Med 1995; 333: 1594-1599.

14. Bouchardy C, Verkooijen HM, Chappuis $P$ et al. Occurrence and impact of genetic factors in breast cancer among the female population in Geneva: creation of the Geneva familial breast cancer registry. Bull Suisse Cancer 2002; 2650: 165-168.

15. Eerola H, Blomqvist C, Pukkala E et al. Familial breast cancer in southern Finland: how prevalent are breast cancer families and can we trust the family history reported by patients? Eur J Cancer 2000; 36: 1143-1148.

16. Douglas FS, O'Dair LC, Robinson M et al. The accuracy of diagnoses as reported in families with cancer: a retrospective study. J Med Genet 1999; 36: 309-312.

17. Sijmons RH, Boonstra AE, Reefhuis J et al. Accuracy of family history of cancer: clinical genetic implications. Eur J Hum Genet 2000; 8: 181-186.

18. Mussio P, Weber W, Brunetti D et al. Taking a family history in cancer patients with a simple questionnaire. Anticancer Res 1998; 18: 28112814.

19. Kerber RA, Slattery ML. Comparison of self-reported and databaselinked family history of cancer data in a case-control study. Am J Epidemiol 1997; 146: 244-248.

20. Anton-Culver H, Kurosaki T, Taylor TH et al. Validation of family history of breast cancer and identification of the BRCA1 and other syndromes using a population-based cancer registry. Genet Epidemiol 1996; 13: 193-205.

21. Bouchardy C. Switzerland, Geneva. In Parkin DM, Whelan SL, Ferlay J et al. (eds): Cancer Incidence in Five Continents, Vol. VII. Lyon, France: IARC Scientific Publications 1997; 666-669.

22. ICD-O: International Classification of Diseases for Oncology. Geneva, Switzerland: WHO 1976.

23. Landis JR, Koch GG. The measurement of observer agreement for categorical data. Biometrics 1977; 33: 159-174.

24. Evans DG, Kerr B, Cade D et al. Fictitious breast cancer family history. Lancet 1996; 348: 1034. 
